\title{
Efectos de las remesas familiares en el crecimiento demográfico de El Salvador
}

Rosa Patricia Vásquez de Alfaro

Docente Utec rosa.vasquez@utec.edu.sv

Recibido: 22/11/2016 - Aceptado: 27/01/ 2017

\section{Resumen}

La investigación realizada busca presentar datos estadísticos sobre los efectos de las remesas familiares en el crecimiento demográfico de El Salvador. Se delimitó en obtener datos sobre remesas familiares y población salvadoreña entre los años 2010 y 2015. Este fenómeno tiene muchas causas, las cuales resulta interesante analizar en profundidad para poder entenderlo. Es por ello que se comparan datos con los que se determina sí el crecimiento demográfico permite que las remesas familiares crezcan, entendiendo como remesa familiar el resultado económico de todas aquellas personas que lograron culminar satisfactoriamente su travesía de emigrante y que aportan económicamente a sus respectivas familias en el país de origen por medio de envíos de dinero.

\section{Palabras clave}

Distribución de la población, remesas, análisis demográfico, movimiento de la población, emigración e inmigración, El Salvador-aspectos socioeconómicos.

\section{Abstract}

This research is aimed to show the statistical data on the effects that family remittances have in the demographic growth of El Salvador. It has been limited to taking into account the data from the 2010-2015 period. This phenomenon is rooted in variety of causes; said causes are of great interest and therefore should be analyzed in depth for a better and clearer understanding of their nature. Based on this, the data has been compared in order to determine whether the demographic growth allows for the family remittances to grow as well. The concept of family remittance is understood as the financial outcome of those who satisfactorily immigrated and who are able to economically support their families in their country of origin, by sending them remittances.

\section{Keywords}

Population distribution, remittances, demographic analysis, population mobility, immigration and migration, El Salvador-socioeconomic factors.

\footnotetext{
Docente de la Facultad de Derecho de la Universidad Tecnológica de El Salvador (Utec).
} 


\section{Introducción}

La migración de los pobladores de El Salvador hacia los Estados Unidos de América es una realidad que hoy en día se ha hecho más común en los diferentes departamentos de aquel país, aventurándose en busca del conocido y denominado 'sueño americano', como una salida alterna a diferentes situaciones económicas. Pero ¿qué es la migración? El término genérico migración se utiliza para describir un movimiento de personas en el que se observa la coacción, incluyendo la amenaza a la vida y su subsistencia, bien sea por causas naturales o humanas [por ejemplo, movimientos de refugiados y de desplazados internos, así como personas desplazadas por desastres naturales 0 ambientales, desastres nucleares o químicos, hambruna o proyectos de desarrollo] (Migración, 2015) https://www.iom. int/es/los-terminos-clave-de-migracion

Se considera que la falta de empleo es una causa principal del porqué un miembro del núcleo familiar debe buscar alternativas de migrar para salir adelante con el sustento diario. En muchos casos los padres son los que deben partir hacia un país desconocido con un futuro incierto. Otro factor involucrado en la migración es la inseguridad que amenaza diariamente a El Salvador, permitiendo que los padres opten por enviar a los niños y jóvenes salvadoreños fuera del país, con el objetivo de que no sean otra estadística más como víctimas de la violencia delincuencial.

Los jóvenes, por otra parte, son un factor de migración en potencia, ya que al salir de sus estudios de educación básica, o los pocos que hoy en día logran culminar sus estudios de bachillerato, se encuentran con una frontera de obstáculos, principalmente la que conlleva a que su educación alcanzada hasta ese momento no le permita encontrar un trabajo que brinde estabilidad laboral y un salario con el que pueda contribuir económicamente con sus padres y hermanos menores, mucho menos tener la oportunidad de adquirir una educación superior.

Al encontrarse en cualquiera de las situaciones que obliguen a emigrar a otro país, se exponen principalmente a una serie de peligros inmersos en su trayectoria, como asaltos, violaciones, secuestros y hasta la muerte. Considerando también de mucha importancia mencionar que el vínculo entre esposos, compañeros de vida y la relación de los padres con sus hijos se afectan a tal grado que se rompen los lazos afectivos en forma total, permitiendo una desintegración familiar con secuelas de abandono y resentimiento, que muchas veces terminan siendo expresados hacia la sociedad de forma equivocada.

\section{Marco legal}

\section{Ley Orgánica del Servicio Estadístico}

La Ley Orgánica del Servicio Estadístico (Lose), en su artículo 12, literales a) y d), dice: "Los censos Nacionales serán levantados en las siguientes épocas: Población, Edificios y Vivienda: cada diez años (en los terminados en cero); Otros Censos: cuando lo determine el Poder Ejecutivo". Así mismo, en su artículo 13, esta ley nos dice: "Los resultados de los censos deberán ser publicados, a más tardar, dos años después de su levantamiento".

El artículo 14, la Lose hace referencia a la obligación de suministrar los datos estadísticos, y nos dice: "Todas las oficinas del Estado, inclusive las del Servicio Exterior, los organismos autónomos y en general, todas las personas naturales y jurídicas domiciliadas o residentes en el país, están obligadas a suministrar a la Dirección General de Estadística y Censos, con la regularidad y término prudencial que ella fije, los datos que requiera el servicio estadístico nacional, y no podrán excusarse de esta obligación".

\section{Método}

Para llevar a cabo el estudio se utilizó el método aplicado en la investigación estadística, y se desarrolló utilizando el ciclo deductivo-inductivo en las siguientes etapas:

a) Recolección de la información.

b) Organización y clasificación de los datos recogidos.

c) Análisis e interpretación de los resultados.

\section{Recolección de datos}

Se visitó instancias como el Banco Central de Reserva de El Salvador (BCR) y la Dirección General de Estadística y Censos para poder obtener datos estadísticos recientes sobre población, remesas, efectos de migración, etc. 


\section{Registros}

Con los datos obtenidos en las instancias correspondientes, se procedió a comparar y conocer los cambios y estructuras, tales como: 1) los cambios en el número de la población, 2) los aumentos de la población por nacimiento, 3) aumento de la población por inmigración, 4) reducción de la población por emigración, y 5) reducción de la población por fallecidos.

\section{Organización y clasificación de datos}

Frente a un conjunto de datos, se clasificaron de acuerdo con criterios convenientes, en una forma simple que permitió ver rápidamente todas las características posibles para obtener conclusiones útiles, ya sea directamente o por medio de cálculos posteriores. Se consideran los siguientes pasos: 1) revisión y corrección de los datos, 2) construcción de tablas de frecuencias, y 3) representación tabular 0 cuadros estadísticos y gráfica.

Resultados

Ingresos mensuales de remesas familiares 2010-2015

\begin{tabular}{|c|c|c|c|c|c|c|c|c|c|c|c|c|c|c|c|}
\hline \multicolumn{16}{|c|}{ Ingresos mensuales de remesas familiares $2010-2015$} \\
\hline \multicolumn{16}{|c|}{ Millones de dólares } \\
\hline Año & Ene & Feb & Mar & Abr & Mayo & Jun & Jul & Agto. & Sept & Oct & Nov & Dic & Total & & $\begin{array}{c}\text { Comportamiento } \\
\text { Aumento y/o } \\
\text { disminución }\end{array}$ \\
\hline 2010 & 230 & 265 & 339 & 298 & 321 & 296 & 289 & 289 & 263 & 272 & 265 & 328 & 3455 & $2 \%$ & + \\
\hline 2011 & 248 & 280 & 332 & 308 & 337 & 298 & 300 & 303 & 287 & 300 & 281 & 354 & 3628 & $5 \%$ & + \\
\hline 2012 & 268 & 316 & 362 & 333 & 349 & 319 & 331 & 313 & 304 & 320 & 292 & 375 & 3880 & $7 \%$ & + \\
\hline 2013 & 279 & 300 & 336 & 355 & 358 & 318 & 331 & 323 & 315 & 332 & 307 & 384 & 3938 & $2 \%$ & + \\
\hline 2014 & 282 & 310 & 374 & 353 & 384 & 353 & 349 & 339 & 331 & 340 & 316 & 402 & 4133 & $5 \%$ & + \\
\hline 2015 & 295 & 316 & 373 & 355 & 386 & 363 & 355 & 356 & 347 & 364 & 338 & 423 & 4270 & $3 \%$ & + \\
\hline
\end{tabular}


Ingresos por año de población de El Salvador 2010-2015

\begin{tabular}{|c|c|c|c|}
\hline & \multicolumn{2}{|c|}{ Millones de dólares } & \\
\hline Año & $\begin{array}{l}\text { Población por } \\
\text { año }\end{array}$ & $\begin{array}{c}\text { \% aumento } \\
\text { y/o } \\
\text { disminución }\end{array}$ & \\
\hline 2010 & 6046757 & 0,28 & + \\
\hline 2011 & 6063721 & 0,28 & + \\
\hline 2012 & 6080939 & 0,28 & + \\
\hline 2013 & 6098675 & 0,29 & + \\
\hline 2014 & 6117145 & 0,30 & + \\
\hline 2015 & 6134885 & 0,29 & + \\
\hline
\end{tabular}

Según el BCR, la migración y las remesas tienen un impacto alto en diferentes rubros de ingresos de la cuenta corriente del país, tal como a continuación se detalla.

Creación propia. Fuente: BCR, 2014.

Inversión de las remesas

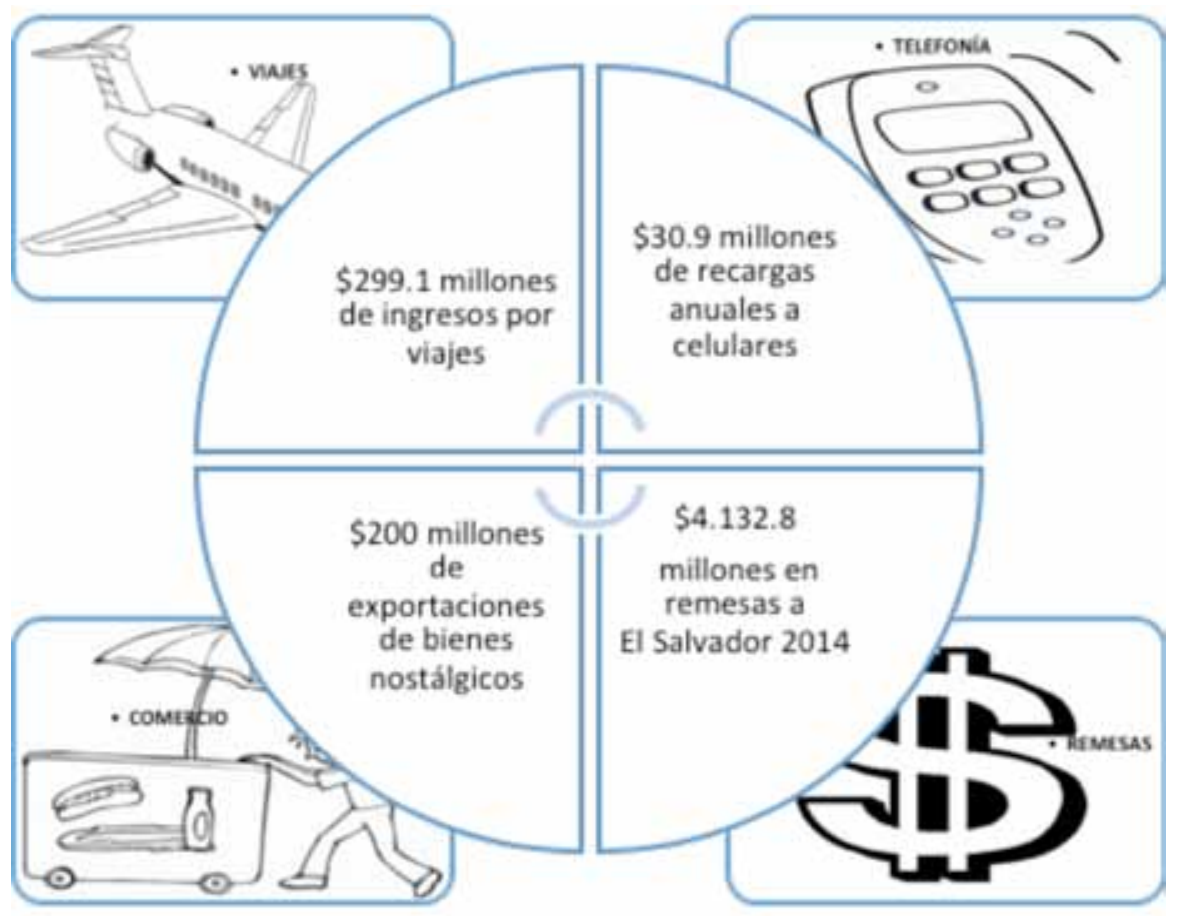




\section{Conclusiones}

Actualmente las remesas en El Salvador influyen en la vida de muchos salvadoreños, ya que en algunos hogares son el pilar fundamental de sobrevivencia.

Según los datos proporcionados por las instituciones formales con respecto al ingreso de remesas en El Salvador, se concretó que se mantienen desde el año 2010 en un constante crecimiento, que es de mucho beneficio para el país. No se puede negar que los países que reciben remesas familiares colaboran en forma indirecta al Estado para resolver necesidades que no son cubiertas por ellos, como educación, vivienda, salud, entretenimiento, etc.
En cuanto a los datos encontrados de la población de El Salvador, al igual que de las remesas familiares, han aumentado desde el año 2010 (revista $B C R, 2011$ ), a pesar de las estadísticas alarmantes de tantas personas que mueren a diario, que desaparecen o que se marchan a otros países, ya sea legal o ilegalmente.

En el cuadro siguiente, que es un comparativo entre remesas familiares y población de El Salvador, se observa un aumento en ambos aspectos. Es de aclarar que esta comparación se hace en forma global, y por eso no se puede determinar si la población crece en comparación con las remesas familiares en esta investigación, ya que se tendría que obtener datos estadísticos de cuánta es la población que realmente recibe remesas, para poder determinar si aumenta o disminuye en forma exacta.

Cuadro comparativo entre remesas familiares y población de El Salvador

\begin{tabular}{|c|c|c|c|c|c|c|c|}
\hline Año & $\begin{array}{c}\text { Remesas } \\
\text { millones } \\
\text { de } \\
\text { dólares }\end{array}$ & $\%$ & $\begin{array}{l}\text { Comporta } \\
\text { miento }\end{array}$ & $\begin{array}{c}\text { Población en } \\
\text { millones }\end{array}$ & $\%$ & $\begin{array}{l}\text { Comporta } \\
\text { miento }\end{array}$ & $\begin{array}{l}\text { Promedio por } \\
\text { poblador } \\
\text { (\$) }\end{array}$ \\
\hline 2010 & 3455.4 & 2,0 & + & 6046757 & 0,28 & + & 571.45 \\
\hline 2011 & 3627.7 & 5,0 & + & 6063721 & 0,28 & + & 598.26 \\
\hline 2012 & 3879.6 & 7,0 & + & 6080939 & 0,28 & + & 637.99 \\
\hline 2013 & 3937.5 & 2,0 & + & 6098675 & 0,29 & + & 645.63 \\
\hline 2014 & 4132.8 & 5,0 & + & 6117145 & 0,30 & + & 675.61 \\
\hline 2015 & 4270 & 3,0 & + & 6134885 & 0,29 & + & 696.02 \\
\hline
\end{tabular}

Cuadro comparativo, creación propia. Fuente: base de datos económica-financiera del BCR al 2016 
Los efectos que se identificaron globalmente en lecturas de artículos de prensa escrita y en línea, como La Prensa Gráfica, El Diario de Hoy, El Faro, El Economista, sobre el fenómeno de las remesas y el crecimiento poblacional de El Salvador, coinciden en que la mayoría de las personas se gastan las remesas en consumismo, lo que permite a El Salvador importar bienes y servicios para complacer cada día a dicha población. Por ese lado, se podría concluir que a medida que crecen las remesas familiares crece la población que gasta ese dinero, ya sea solo en consumismo o en otras actividades que benefician o no al país.

\section{Referencias}

Digestyc (6 de mayo de 62016). Digestyc. Consultado: 20 de mayo, 2016. Disponible en: http://www. digestyc.gob.sv/index.php/novedades/avisos/588- compendio-estadistico-2012-2013.html:http:// www.digestyc.gob.sv/index.php/novedades/ avisos/588-compendio-estadistico-2012-2013.html Factbook, C.W. (5 de mayo de 2016). http://Www.indexmundi.

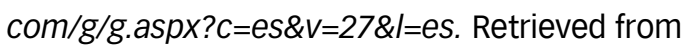

Digestyc (6 de mayo de 2016). Digestyc. Obtenido de http:// www.digestyc.gob.sv/index.php/novedades/ avisos/588-compendio-estadistico-2012-2013. html:http://www.digestyc.gob.sv/index. php/novedades/avisos/588-compendioestadistico-2012-2013.html

Factbook, C.W. (5 de mayo de 2016). http://WWW. indexmundi.com $/ g / g$. asp $x$ ? c $=e s \& V=27 \& /=e s$. Obtenido de http://www.indexmundi.com/g/g. aspx?c=es\&v=27\&l=es:http://www.indexmundi. $\mathrm{com} / \mathrm{g} / \mathrm{g}$. aspx? $\mathrm{C}=\mathrm{es} \& \mathrm{~V}=27 \& \mathrm{l}=\mathrm{es}$

Banco Central de Reserva, recuperado el 15 de mayo 2016 de http://www.bcr.gob.sv/esp/ 